\title{
Association of Plant Color and Pericarp Color with Colonization of Grain by Members of Fusarium and Alternaria in Near-Isogenic Sorghum Lines
} Deanna L. Funnell, USDA-ARS, Wheat, Sorghum and Forage Research, and Department of Plant Pathology, Uni-
versity of Nebraska, Lincoln 68583-0937; and Jeffrey F. Pedersen, USDA-ARS, Wheat, Sorghum and Forage Re-
search, and Department of Agronomy and Horticulture, University of Nebraska, Lincoln 68583-0937

\begin{abstract}
Funnell, D. L., and Pedersen, J. F. 2006. Association of plant color and pericarp color with colonization of grain by members of Fusarium and Alternaria in near-isogenic sorghum lines. Plant Dis. 90:411-418.

White sorghum (Sorghum bicolor) grain from tan plants is more desirable for human or animal consumption. Colonization by Fusarium and Alternaria spp. was assessed for near-isogenic lines differing in wound response (purple or tan) and pericarp color (red or white) in field-grown grain and in greenhouse-grown plants. Seeds were screened on a semi-selective medium for Alternaria and Fusarium. Significantly fewer fungal colonies were obtained from tan plants with white seed, and fewer numbers of Alternaria colonies were obtained from white seed, regardless of plant color, from an irrigated field, while there were no differences in fungal composition of seeds grown at a nonirrigated field. Screening of seed from the nonirrigated field on Fusarium semi-selective medium yielded fewer Fusarium isolations from seed grown on purple plants compared with seed from tan plants. When inoculated with Alternaria sp. and F. moniliforme, there can be no differences in lesion lengths on tan/white plants when compared with purple/red plants in most assays; in one assay, tan/white plants had smaller lesion lengths following inoculation with $F$. moniliforme. These results suggest that plants with white seeds were as resistant as plants with the red pericarp trait to colonization by Alternaria and Fusarium spp. However, the results also suggest that under appropriate environmental conditions seed from tan plants may be more susceptible to Fusarium spp. than seed from purple plants.
\end{abstract}

Additional keywords: food-grade sorghum, Fusarium verticillioides, grain mold, mycotoxigenic fungi, wound inoculation

Sorghum (Sorghum bicolor (L.) Moench) pericarp pigments can affect grain quality. Pigments found in vegetative parts of the plant and in the peduncle and glumes of flowers $(12,44)$ also may indirectly impact sorghum grain quality. Pigments associated with the "purple wound response" accumulate following mechanical injury, insect feeding, or pathogen invasion $(22,31)$. Grain with nonpigmented pericarps (white seed), grown on tan plants that lack the purple wound response, is highly desirable as livestock feed and for human consumption $(4,39)$.

Infection by fungal pathogens can reduce sorghum grain quality and/or yield

Corresponding author: Deanna L. Funnell

E-mail: dfunnell@unlserve.unl.edu

Mention of trade names or commercial products in this article is solely for the purpose of providing specific information and does not imply recommendation or endorsement by the U.S. Department of Agriculture.

Accepted for publication 28 October 2005.

DOI: 10.1094/PD-90-0411

This article is in the public domain and not copyrightable. It may be freely reprinted with customary crediting of the source. The American Phytopathological Society, 2006.
$(6,36)$. Additionally, stored grain or plant material used for forage or in the making of silage can be contaminated with mycotoxin-producing fungi $(11,42)$. Although less desirable from an agronomic perspective, plant pigments are associated with protection against invasion by insects and pathogens $(2,8,31,44)$. Sorghum leaf pigments include 3-deoxyanthocyanidin phytoalexins involved in plant defense $(30,46)$. The sorghum pericarp pigments 3-deoxyanthocyanins $(3,32)$ also may have protective qualities $(10,48)$.

Sorghum germ plasm has been screened to assess the role pigments may play in defense against pests $(5,45)$. However, grain hardness or plant height $(2,16)$ also may contribute to protection against insects and pathogens. Thus, the protective role of anthocyanin and anthocyanadin pigments is unclear. Recently developed near-isogenic sorghum lines that vary in plant color (purple versus tan) and pericarp color (red versus white) exhibit favorable agronomic qualities (39). Among the four phenotypes (purple/red, purple/white, $\tan / \mathrm{red}$, and $\tan /$ white), there were no significant differences in germination, seedling vigor, and field performance. However, when plant color and pericarp color phenotypes were considered separately, germination and field emergence were significantly better for plants having either purple plant color or red pericarp phenotypes (39). It was proposed that these differences may be due to greater colonization and/or infection by fungi of plants with the white-grain or tan plant color phenotypes (39). Therefore, it was incumbent to test the hypothesis that sorghum with white grain and tan plant-color are more susceptible to colonization by fungi than plants carrying seed with red pericarps with the purple wound response.

In this work, we assessed colonization of field-grown sorghum grain by Alternaria spp. and Fusarium spp. Isolates of these genera were obtained from fieldgrown grain using two different semiselective media $(1,28)$. These fungal species were chosen because of prevalence in both diseased and asymptomatic sorghum grain $(23,43,49)$. Additionally, greenhouse inoculation assays (18) were conducted using an Alternaria sp. isolated from sorghum seed and a Fusarium moniliforme sensu lato isolate pathogenic on sorghum.

\section{MATERIALS AND METHODS}

Field experiment. Twenty near-isogenic lines differing in plant color and pericarp color had been previously developed (39). The lines ( $97 \%$ identical) are S8 segregates of a single $\mathrm{S} 3$ family from the $\mathrm{BC} 1$ generation of the cross (BTx386 ms $3 \times$ BTx630) $(m s 3 \times$ BTx630) (39). The lines were grown in the field during 2002 at

Table 1. Rainfall (Ithaca, NE, 2002 and Lincoln, NE, 2003) and irrigation (Ithaca, 2002) monthly totals $(\mathrm{cm})$

\begin{tabular}{lcc}
\hline Water (cm) & $\begin{array}{c}\text { Ithaca, } \\
\mathbf{2 0 0 2}^{\mathbf{a}}\end{array}$ & $\begin{array}{c}\text { Lincoln, } \\
\mathbf{2 0 0 3}^{\mathbf{b}}\end{array}$ \\
\hline Rainfall, May & $3.63^{\mathrm{c}}$ & $0.20^{\mathrm{c}}$ \\
Rainfall, June & 4.06 & 16.89 \\
Irrigation, June & 5.00 & $\mathrm{NA}^{\mathrm{d}}$ \\
Rainfall, July & 3.15 & 2.59 \\
Irrigation, July & 5.00 & $\mathrm{NA}$ \\
Rainfall, August & 16.74 & 3.30 \\
Irrigation, August & 5.00 & $\mathrm{NA}$ \\
Rainfall, September & 2.84 & $9.68^{\mathrm{e}}$ \\
Rainfall, October & 9.27 & $\mathrm{NA}$ \\
Rainfall, November & $0.50^{\mathrm{e}}$ & $\mathrm{NA}$ \\
\hline
\end{tabular}

a Planting date: May 21. Harvest date: November 8 .

b Planting date: May 21. Harvest date: September 24.

c From date of planting.

d Not applicable.

e Until date of harvest. 
Ithaca, NE and 2003 in Lincoln, NE, for assessment of fungal colonization of grain. Among the 20 near-isogenic lines, there were five of each phenotype: purple (plant color)/red (pericarp color), purple/white, $\tan / \mathrm{red}$, and $\tan /$ white. Irrigation was applied at Ithaca; fields at the Lincoln location were not irrigated (Table 1). At each location, two-row plots for each of the 20 lines were randomized within each of four repetitions. Seed source (produced in 1999) was the same for both plantings. Irrigation and rainfall totals for Ithaca, 2002 and rainfall totals for Lincoln, 2003 are shown in Table 1. Nitrogen fertilizer was applied prior to planting at both locations at $157 \mathrm{~kg} \mathrm{ha}^{-1}$. At the Lincoln location, propachlor [2-chloro- $N$-(1-methylethyl)- $N$-phenylacetamide] and atrazine [6-chloro- $n$-ethyl- $N$ '-(1-methylethyl)-1,3,5trazine-2,4-diamine] were applied at 3.36 and $1.1 \mathrm{~kg} \mathrm{ha}{ }^{-1}$, respectively, approximately 14 days postemergence. In 2002, bentazon [2-(1-methylethyl)-1H-2,1,3-benzothiadiazin $4(3 \mathrm{H})$-one-2,2-dioxide] was added to the postemergence application at $0.28 \mathrm{~kg} \mathrm{ha}^{-1}$ for velvetleaf (Abutilon theophrasti (Medik)) control. Grain hardness, assessed using a wheat single kernel characterization system, determined that mean hardness ranged from 80 (purple/red plants) to 82 (tan/white plants) (90 to 110 is defined as hard and 40 is defined as soft) (38).

Isolation of fungi from field-grown seed. Grain was removed from heads of 10 randomly chosen plants within each plot. Seeds were surface-sterilized in $95 \%$ etha- nol followed by $1 \%$ sodium hypochlorite with $0.01 \%$ Tween 20 (51). From 14 to 20 seeds per plot were plated onto DCPA medium (1) containing dichloran (Ultra Scientific, North Kingston, RI) and chloramphenicol (Sigma Chemical Co., St. Louis, MO). A randomly chosen subset of 16 plots from Lincoln, 2003, also were plated onto PCNB medium (28), which contains streptomycin (Sigma) and the fungicide pentachloronitrobenzene (Terrachlor, Uniroyal Company, Middlebury, CT). A note was made of seed that appeared molded, discolored, or nonuniform in shape or size to assess possible differences between seed from different plots or locations.

Individual fungal colonies growing out from seed onto the medium were trans-

Table 2. Isolations of fungi and enumeration of Alternaria species, Fusarium moniliforme, and Fusarium species from seed grown at Ithaca, NE, in 2002 and selected on DCPA medium ${ }^{\mathrm{a}}$

\begin{tabular}{|c|c|c|c|c|c|c|}
\hline Plant color & Pericarp color & No. of seeds tested & $\begin{array}{c}\text { Fungal isolations/ } \\
\text { seed }\end{array}$ & $\begin{array}{c}\text { Alternaria } \text { spp./ } \\
\text { seed }\end{array}$ & $\begin{array}{c}\text { F. moniliformel } \\
\text { seed }\end{array}$ & $\begin{array}{c}\text { Other Fusarium } \\
\text { spp./seed }\end{array}$ \\
\hline \multicolumn{7}{|c|}{ By plant and pericarp color } \\
\hline Purple & Red & 335 & $1.185 \pm 0.051$ & $0.709 \pm 0.057$ & $0.018 \pm 0.011$ & $0.039 \pm 0.018$ \\
\hline Purple & White & 333 & $1.165 \pm 0.051$ & $0.610 \pm 0.057$ & $0.031 \pm 0.011$ & $0.089 \pm 0.018$ \\
\hline Tan & Red & 343 & $1.192 \pm 0.051$ & $0.655 \pm 0.057$ & $0.020 \pm 0.011$ & $0.064 \pm 0.018$ \\
\hline Tan & White & 341 & $0.997 \pm 0.051 * \mathrm{~b}$ & $0.542 \pm 0.057$ & $0.023 \pm 0.011$ & $0.055 \pm 0.018$ \\
\hline \multicolumn{7}{|c|}{ By plant color } \\
\hline Purple & - & 668 & $1.175 \pm 0.044$ & $0.660 \pm 0.046$ & $0.024 \pm 0.008$ & $0.064 \pm 0.013$ \\
\hline Tan & - & 684 & $1.094 \pm 0.044 *$ & $0.598 \pm 0.046$ & $0.022 \pm 0.008$ & $0.060 \pm 0.013$ \\
\hline \multicolumn{7}{|c|}{ By pericarp color } \\
\hline- & Red & 678 & $1.188 \pm 0.044$ & $0.682 \pm 0.046$ & $0.019 \pm 0.008$ & $0.051 \pm 0.013$ \\
\hline- & White & 674 & $1.081 \pm 0.044^{*}$ & $0.576 \pm 0.046^{*}$ & $0.027 \pm 0.008$ & $0.072 \pm 0.013$ \\
\hline
\end{tabular}

a Least squares means (LSM) and standard errors are shown.

$\mathrm{b} *$ Indicates number is significantly less than other(s) in comparison at $P \leq 0.05$.
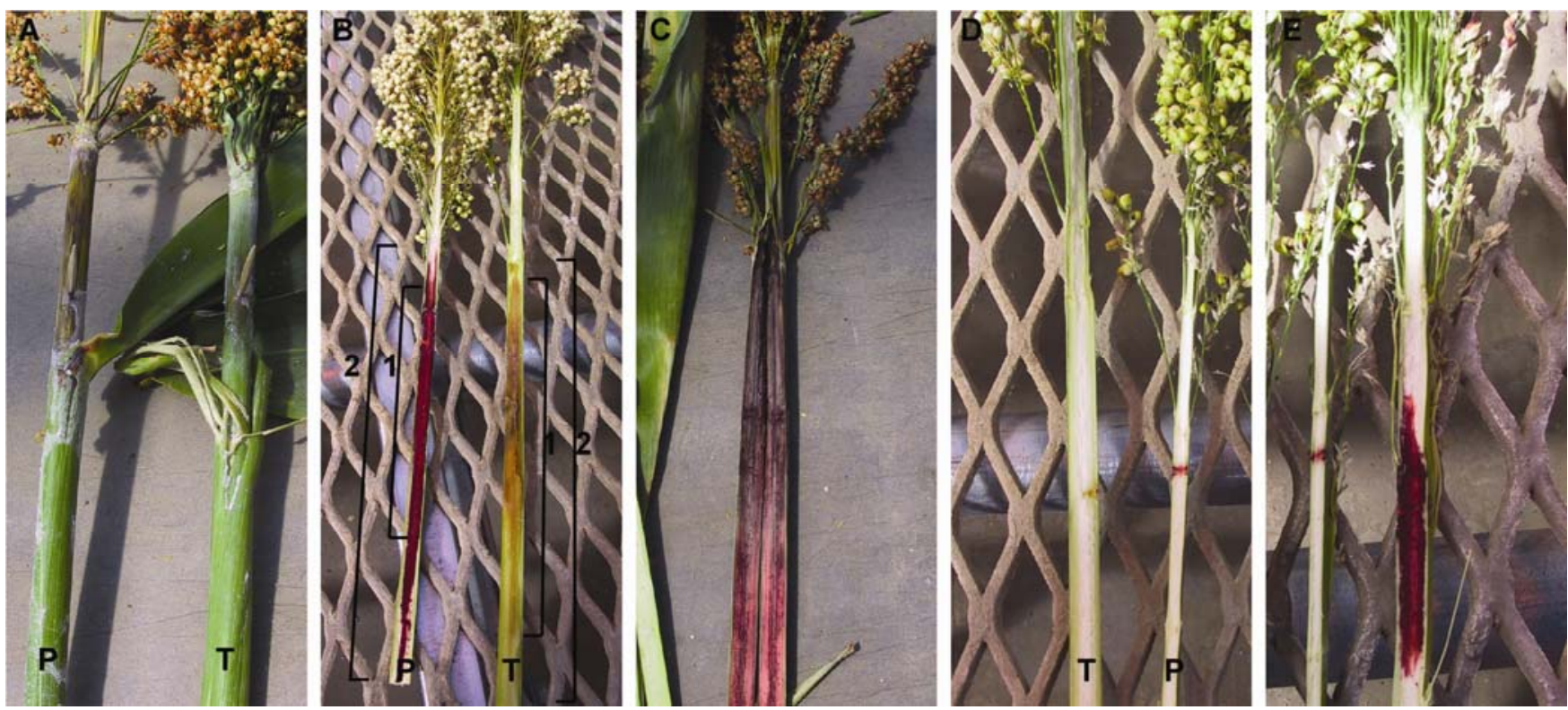

Fig. 1. Response of purple plants and tan plants to wound inoculation with Fusarium moniliforme (A, B, and C) or sterile broth $(\mathbf{C}$ and D). A, Whole sorghum head peduncles 22 days following wound inoculation with toothpicks incubated in broth with $F$. moniliforme. Peduncles from a purple plant $(\mathrm{P})$ with red seed (left) and from a tan plant (T) with red seed (right) are shown. B, Sorghum head peduncles split longitudinally for measurement of plant response 22 days following wound inoculation with F. moniliforme. Brackets labeled " 1 " indicate measurement 1, brackets labeled " 2 " indicate measurement 2. Peduncles from a purple plant with white seed (left), and a tan plant with white seed (right) are shown. C, Example of lesion extending throughout peduncle. Both sides of a dissected peduncle from a purple plant with red seed are shown. D and E, Longitudinally split peduncles exhibiting response of plants to inoculation with sterile broth. All plants shown have grain with white pericarp. D, Peduncles from plants showing a common response to mock inoculation. The tan plant is on the left and the purple plant is on the right. E, Range of responses to mock inoculation in peduncles from two purple plants. 
ferred to half-strength potato dextrose agar $(1 / 2 \times$ PDA; made from potato dextrose broth purchased from EM Scientific, Gibbstown, NJ) to assess colony morphology. Fungal isolates were transferred to water agar, with an approximately $0.5 \mathrm{~cm}^{2}$ sterile filter paper placed over the inoculation site on the agar surface (34). Fusarium spp. were identified, whenever possible, using morphological features, spore types, and conidiophore structures (20,29). Isolates with characteristics and structures consistent with Fusarium verticillioides (Sacc.) Nirenberg (=F. moniliforme) (33) were defined as belonging to Fusarium moniliforme sensu lato $(23,24,40)$, which was referred to as $F$. moniliforme in the text. For purposes of statistical analyses, all other Fusarium spp. were counted as a single group.

Assessments of colonization by fungi in grain from the complete set of field-grown plants were analyzed using Proc MIXED (SAS Institute, Cary, NC). Plant color, pericarp color, line, and environment (due to application of irrigation at Ithaca, 2002) were considered fixed, and replication was considered random in the model. The experimental design was a randomized complete block with four replications with lines nested in phenotype. Preliminary analyses indicated that environmental interactions with line or phenotype were significant for multiple traits. Therefore, separate analyses were conducted for each environment. Because multiple plots had seed with no $F$. moniliforme or other Fusarium spp. recovered, data were normalized using arcsine transformation. The results were equivalent for both transformed and untransformed. Therefore, only nontransformed least squares means (LSM) with standard errors are presented.

Apparent effectiveness of field blocking was lost upon random selection of the small subset of 16 random lines used for the PCNB experiment. These results were analyzed using Proc GLM (SAS) since only fixed effects, line, plant color, and pericarp color were included in the model. Means and standard deviations are reported.

Greenhouse experiments. For each assay, plants were grown and inoculated in the following way. Seed from each line was sown into a standard mix in $25-\mathrm{cm}$ pots, grown in a greenhouse, and thinned to two plants per pot. Two weeks following anthesis (12 to 15 weeks after planting), the peduncles were inoculated by wounding with toothpicks incubated in broth cultures consisting of $5 \mathrm{ml}$ of potato dextrose broth (PDB) in a 50-ml tube containing 10 sterile toothpicks (18). Fungal broth cultures were inoculated with a plug from a 1-week-old plate culture of $F$. moniliforme ( $F$. verticillioides; M-3790, obtained from Fusarium Research Center, Pennsylvania State University) or an Alternaria sp. isolate (H02-773-s-3) (obtained from seed grown at Lincoln) cultured for 1 week on 1/2x PDA (18). Sterile broth cultures for mock inoculations and fungal cultures were incubated at $20^{\circ} \mathrm{C}$ for 10 days (18). To measure the resulting lesions (18 or 22 days postinoculation [dpi]), the peduncles were split longitudinally. Up to two measurements were made: the length of the lesion $(\mathrm{mm})$ that spans the radius of the peduncle (measurement 1), and the total length of the lesion, which included discontinuous discoloration, if present (measurement 2) (18). If there was no discontinuous area visible at the ends of the lesion, measurement 1 and measurement 2 were equivalent. Occasionally, lesions extended into the vegetative stalk. Such lesions were measured as the length of the peduncle (approximately $300 \mathrm{~mm}$ ). Four assays were conducted.

For assay 1, one plant in each pot was inoculated with $F$. moniliforme and the other plant with the Alternaria sp. isolate. Up to four plants per line, five lines per phenotype, for up to 20 plants per phenotype, were inoculated with each isolate. Lesions were measured 18 dpi.

For assay 2, plants were inoculated with F. moniliforme or mock inoculated. Up to

Table 4. Isolations of fungi and enumeration of Alternaria species, Fusarium moniliforme, and Fusarium species from seed grown at Lincoln, NE, in 2003 and selected on PCNB medium ${ }^{\mathrm{a}}$

\begin{tabular}{|c|c|c|c|c|c|}
\hline Phenotype & $\begin{array}{c}\text { No. of } \\
\text { seeds tested }\end{array}$ & $\begin{array}{c}\text { Fungal } \\
\text { isolations/seed }\end{array}$ & $\begin{array}{c}\text { Alternaria } \\
\text { spp./seed }\end{array}$ & $\begin{array}{c}F . \begin{array}{c}\text { moniliformel } \\
\text { seed }\end{array} \\
\text { sed }\end{array}$ & $\begin{array}{c}\text { Other Fusarium } \\
\text { spp./seed }\end{array}$ \\
\hline \multicolumn{6}{|c|}{ By plant color } \\
\hline Purple & 132 & $0.660 \pm 0.320$ & $0.341 \pm 0.249$ & $0.000^{\mathrm{b}} \pm 0.000$ & $0.066 \pm 0.090 * \mathrm{c}$ \\
\hline Tan & 119 & $0.580 \pm 0.285$ & $0.168 \pm 0.150$ & $0.076 \pm 0.056$ & $0.143 \pm 0.089$ \\
\hline \multicolumn{6}{|c|}{ By pericarp color } \\
\hline Red & 117 & $0.701 \pm 0.276$ & $0.296 \pm 0.241$ & $0.037 \pm 0.054$ & $0.155 \pm 0.103$ \\
\hline White & 134 & $0.493 \pm 0.277$ & $0.235 \pm 0.216$ & $0.029 \pm 0.054$ & $0.045 \pm 0.042$ \\
\hline
\end{tabular}

a Totals of a subset of seed reported in Table 3 that was plated onto both DCPA and PCNB at the same time.

b 0.000 Indicates that no F. moniliforme were isolated from grain of purple plants on PCNB.

c * Indicates number is significantly less at $P \leq 0.05$. four plants per line (up to 20 plants of each phenotype) were inoculated with $F$. moniliforme, and up to two plants per line (up to 10 plants of each phenotype) were mock inoculated. Within a single pot, one plant was inoculated with $F$. moniliforme and the second plant was mock inoculated, or both plants were inoculated with $F$. moniliforme. Measurements were made $18 \mathrm{dpi}$.

For assays 3 and 4, up to six plants per line (up to 30 plants of each phenotype) were inoculated with $F$. moniliforme and up to two plants per line (up to 10 plants of each phenotype) were mock inoculated. Both plants in a given pot were inoculated with the same culture. Plant lines with the white pericarp phenotype were tested in assay 3; lines having the red pericarp phenotype were tested in assay 4 . Measurements in both assays 3 and 4 were made 22 dpi.

Assays 1 and 2 were conducted as splitplot experiments, with lines being wholeplots and inoculum being subplots. The design was completely random, with line, pericarp color, plant color, and inoculum considered fixed effects, and pot considered random. Due to plant mortality, unequal numbers of treatment combinations were available for both inoculation and assessment. Analyses were conducted using Proc MIXED (SAS), considering lines nested within phenotype. The design for assays 3 and 4 was again completely random, but it differed in that subsampling of identical treatment combinations occurred in each pot. Plant color, line, and inoculum were considered fixed effects, and pot was considered random. Again, due to mortality, unequal numbers of treatment combinations were available for

Table 3. Isolations of fungi and enumeration of Alternaria species, Fusarium moniliforme, and Fusarium species from seed grown at Lincoln, NE, in 2003 and selected on DCPA medium ${ }^{\mathrm{a}}$

\begin{tabular}{lcccccc}
\hline Plant color & Pericarp color & No. of seeds tested & $\begin{array}{c}\text { Fungal isolations/ } \\
\text { seed }\end{array}$ & $\begin{array}{c}\text { Alternaria spp./ } \\
\text { seed }\end{array}$ & $\begin{array}{c}\text { F. moniliforme/ } \\
\text { seed }\end{array}$ & $\begin{array}{c}\text { Other Fusarium } \\
\text { spp./seed }\end{array}$ \\
\hline Purple & Red & 317 & $1.141 \pm 0.083$ & $0.476 \pm 0.107$ & $0.009 \pm 0.009$ & $0.029 \pm 0.011$ \\
Purple & White & 339 & $1.068 \pm 0.083$ & $0.526 \pm 0.107$ & $0.000^{\mathrm{b}} \pm 0.009$ & $0.011 \pm 0.011$ \\
Tan & Red & 296 & $1.069 \pm 0.083$ & $0.546 \pm 0.107$ & $0.021 \pm 0.009$ & $0.036 \pm 0.012$ \\
Tan & White & 306 & $1.084 \pm 0.083$ & $0.525 \pm 0.107$ & $0.012 \pm 0.009$ & $0.027 \pm 0.011$ \\
\hline
\end{tabular}

${ }^{a}$ Least squares means (LSM) and standard errors are listed. $P$ value for fungal isolations per seed is 0.371 , for Alternaria spp./seed is 0.507 , for $F$. moniliforme/seed is 0.893 , and for isolations of other Fusarium spp./seed is 0.705 .

b 0.000 Indicates no F. moniliforme. 
inoculation and assessment. Appropriate error degrees of freedom were calculated by specifying the KENWARDROGER option in the model to account for unequal sample sizes.

\section{RESULTS}

Fungal colonization of seed from plant color/pericarp color near-isogenic lines. Field-grown seed harvested from plants grown at Ithaca during the 2002
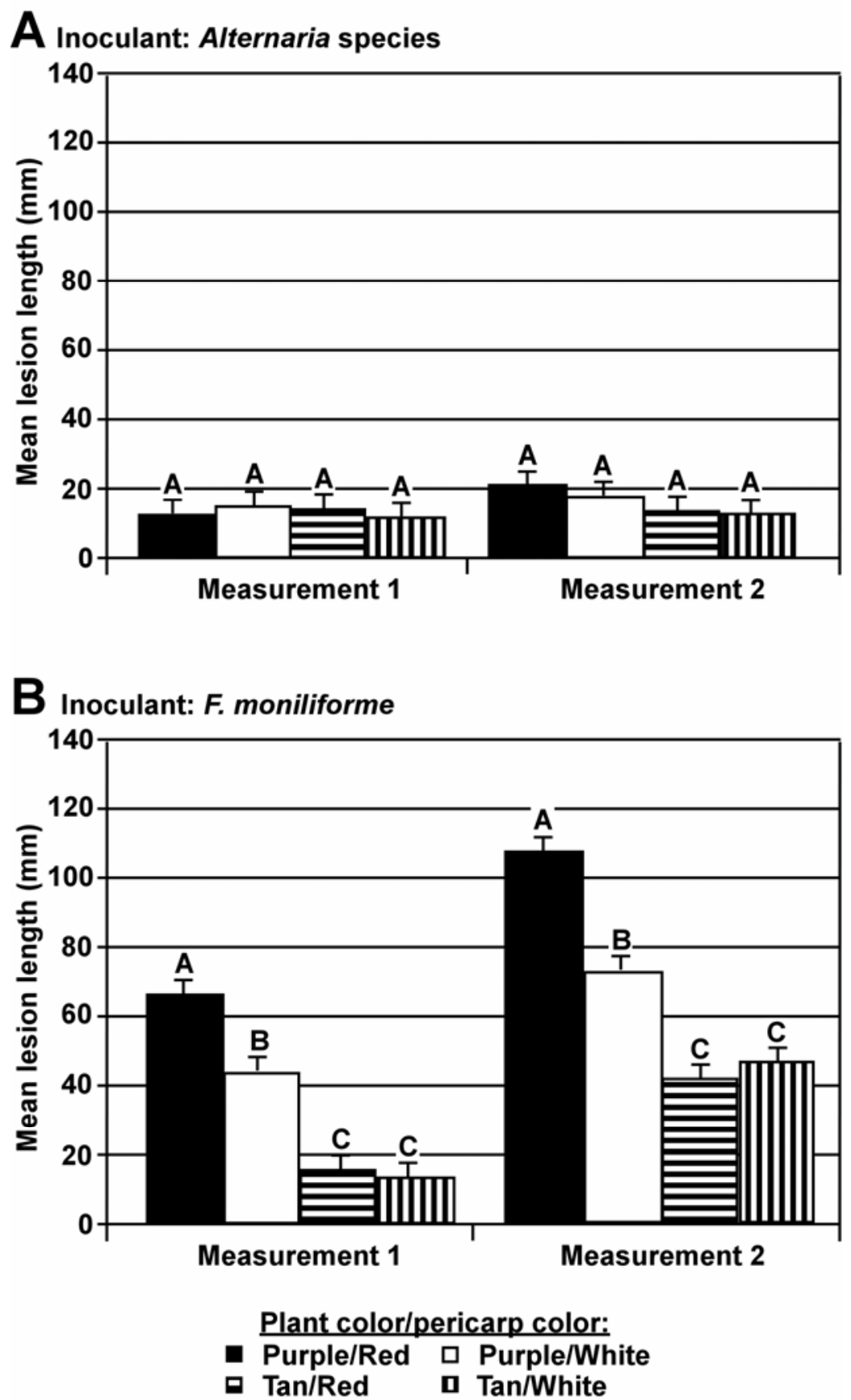

Fig. 2. Response of plant color/pericarp color lines to inoculation with an Alternaria species field isolate and a Fusarium moniliforme isolate pathogenic on sorghum assay 1. Mean (LSM) lesion lengths $(\mathrm{mm})$ for the first measurement and the second measurement 18 days following inoculation of plant color/pericarp color lines. Positive standard errors are shown. Bars marked with different letters for each measurement are statistically significant at $P \leq 0.05$. A, Inoculation of 20 purple/red, 20 purple/white, 20 tan/red, and 19 tan/white plants with Alternaria species. There were no significant differences between lines for measurement 1 or measurement 2. B, Inoculation of 20 purple/red plants, 20 purple/white plants, 19 tan/red plants, and 18 tan/white plants with F. moniliforme.
Therefore, the two environments were analyzed separately. For seed grown at Ithaca (irrigated) in 2002, tan plants having seeds with white pericarp had significantly fewer numbers of total fungal colonies isolated $(P=0.022)$ than the other three phenotypes (Table 2). Numbers of Alternaria colonies isolated were significantly less from lines having white seeds than from lines having red seeds $(P=0.031)$ (Table 2). There were no significant differences in numbers of $F$. moniliforme isolations or for isolations of Fusarium species other than $F$. moniliforme when comparing the four plant color/pericarp color phenotypes or when comparing plant color or pericarp color (Table 2). For field-grown seed collected from Lincoln (nonirrigated) in 2003, there were no significant differences in any of the response variables: mean number of fungal isolations per seed, mean number of Alternaria colonies per seed, mean numbers of $F$. moniliforme isolations per seed, or mean number of other Fusarium spp. isolated per seed, following plating of seed and selection of fungal outgrowths on DCPA medium when considering the four plant color/pericarp color phenotypes (Table 3 ) or when considering only plant color or pericarp color.

Seeds from the random subset of plants sampled from plots at Lincoln, 2003, plated onto DCPA medium, also were plated onto PCNB medium (Table 4). When fungal outgrowths from seed were selected on PCNB medium, mean Fusarium spp. other than $F$. moniliforme were significantly less $(P=0.047)$ in seed grown on plants with the purple color phenotype than those grown on tan plants (Table 4). There were no significant differences among the four plant color/pericarp color phenotypes for any of the measurements: colonies isolated per seed, numbers of Alternaria colonies, numbers of $F$. moniliforme, and numbers of Fusarium species other than $F$. moniliforme (Table 4). For selection of fungal outgrowths on DCPA for seeds from the random subset, there were no significant differences in the measured traits for plant color, pericarp color, or the four plant phenotypes (Table 3 and data not shown).

Besides F. moniliforme, other Fusarium spp. observed from seed collected from plant color/pericarp color plants grown at Ithaca in 2002 were (in alphabetical order): F. anthophilum (A. Braun) Wollenw. (33), $F$. avenaceum (Fr.) Sacc., F. chlamydosporum Wollenw. Reinking, F. graminum Corda, F. lateritium (Nees), F. proliferatum (Matsushima) Nirenberg (33), $F$. semitectum Berk. \& Rav., F. solani (Mart.) Appel \& Wollenw. Emen. Snyd. \& Hans., F. subglutinans (Wollenw. \& Reinking) Nelson, Tousson \& Marasas comb. nov., and $F$. thapsinum Klittich, Leslie, Nelson et Marasas sp. nov. (20). Fusarium spp. other than $F$. moniliforme isolated from plant color/pericarp color seed collected 
from plants grown at Lincoln in 2003 included: $F$. acuminatum Ell. \& Ev. sensu Gordon (15), F. equiseti (Corda) Sacc. sensu Gordon (15), F. solani, $F$. proliferatum, F. subglutinans, and F. thapsinum.

Response of plant color/pericarp color plants to wound inoculation with an Alternaria isolate and an $F$. moniliforme isolate. Following inoculation of peduncles of purple and tan plants, lesions on tan plants were different in color from purple plants, due to the lack of pigments that cause the purple wound response. Although a discoloration of the peduncle was apparent in $F$. moniliforme-inoculated tan plants, lesions were lighter in color than lesions on purple plants infected with $F$. moniliforme (Fig. 1A). Upon splitting the peduncle, dark red lesions were apparent in the purple-colored plants that included the entire width of the peduncle (measurement 1), with lesion edges often lighter in color and not spanning the peduncle (measurement 2) (Fig. 1B). The relatively dark lesion that encompasses the diameter of the peduncle (measurement 1 ) following inoculation of tan plants with fungi is light brown to tan, while measurement 2 , which includes the less discrete portion of the lesion, is lighter though still discernible and may be woody in appearance (Fig. 1B). Lesions can extend beyond the peduncle and into the stalk. This was observed in both tan and purple plants; a purple plant is shown in Figure 1C.

Assay 1: inoculation with an Alternaria isolate and an F. moniliforme isolate. Mean lesion lengths resulting from inoculation with $F$. moniliforme were significantly greater than those resulting from inoculation with an Alternaria isolate
(H02-773-s-3) ( $P=0.0001$; Fig. 2). Inoculum interactions with plant color (for both measurements, $P<0.0001)$ or pericarp color for measurement $2(P=0.004)$ also were significantly different. There were no significant differences among phenotypes for either measurement following inoculation with the Alternaria sp. isolate (Fig. 2A).

Inoculation with $F$. moniliforme in assay 1 resulted in significant differences among the four plant color/pericarp color phenotypes when considering both the first and the second lesion measurement (Fig. 2B). Both measurements yielded significantly greater mean lengths following inoculation of purple plants when compared with all tan plants $(P<0.0001)$. Pericarp color did not appear to affect mean lesion length following inoculation of tan plants (for measurement $1, P=0.7540$, for measurement $2, P=0.401$ ), but red-seeded plants exhibited longer mean lesion lengths when compared with lesions produced on whiteseeded plants inoculated with $F$. moniliforme (for measurement $1, P=0.016$; for measurement 2, $P=0.001$ ) (Fig. 2B).

Assay 2: inoculation with an F. moniliforme isolate and with sterile broth. A concern was raised that the greater mean lesion lengths observed in assay 1 following inoculation of purple plants with $F$. moniliforme may be due, at least in part, to the wound response, and indirectly due to fungal invasion. Therefore, inoculation with sterile toothpicks, incubated in sterile PDB alongside of $F$. moniliforme-infested toothpicks, was performed. On some purple and tan plants, inoculation with toothpicks incubated in sterile broth resulted in localized discolorations, from less than 1 $\mathrm{mm}$ to $5 \mathrm{~mm}$ in length (Fig. 1D and E). Larger responses (Fig. 1E) may be the result of a wound response but also could be the result of incidental contamination via the wound or the exposed broth-soaked toothpick. In assay 2 , there were significant differences between inocula, $F$. moniliforme culture versus sterile PDB $(P$ $<0.0001$ ), and no significant interaction of inoculum with plant color or pericarp color. The mean lesion lengths following each treatment across all plant color/pericarp color phenotypes for measurement 1 was $101.7 \mathrm{~mm}$ versus $32.8 \mathrm{~mm}$, and for measurement 2, $127.6 \mathrm{~mm}$ versus $35.3 \mathrm{~mm}$, for inoculation with $F$. moniliforme or sterile broth, respectively. No significant differences due to the interactions of plant color with pericarp color (for measurement $1, P=0.469$, for measurement $2, P=0.164$ ) accounted for significant differences among the four phenotype classes following inoculation with $F$. moniliforme (for measurement $1, P=$ 0.042 , for measurement 2, $P=0.286$ ) (Fig. $3)$. There were no significant differences for measurements 1 and 2 following mock inoculations with sterile broth (Fig. 3, measurement 2 is shown).

Assays 3 and 4: comparison of purple and tan plants inoculated with F. moniliforme. Evidence from previous work has indicated that the red pericarp trait can contribute to pigmentation in nonreproductive plant parts (7). Therefore, two assays were conducted to directly assess the effects of pigments involved in the purple wound response. Assay 3 involved only white-seeded plants; assay 4 had only redseeded plants (Fig. 4). In these two assays, there were no significant differences be-

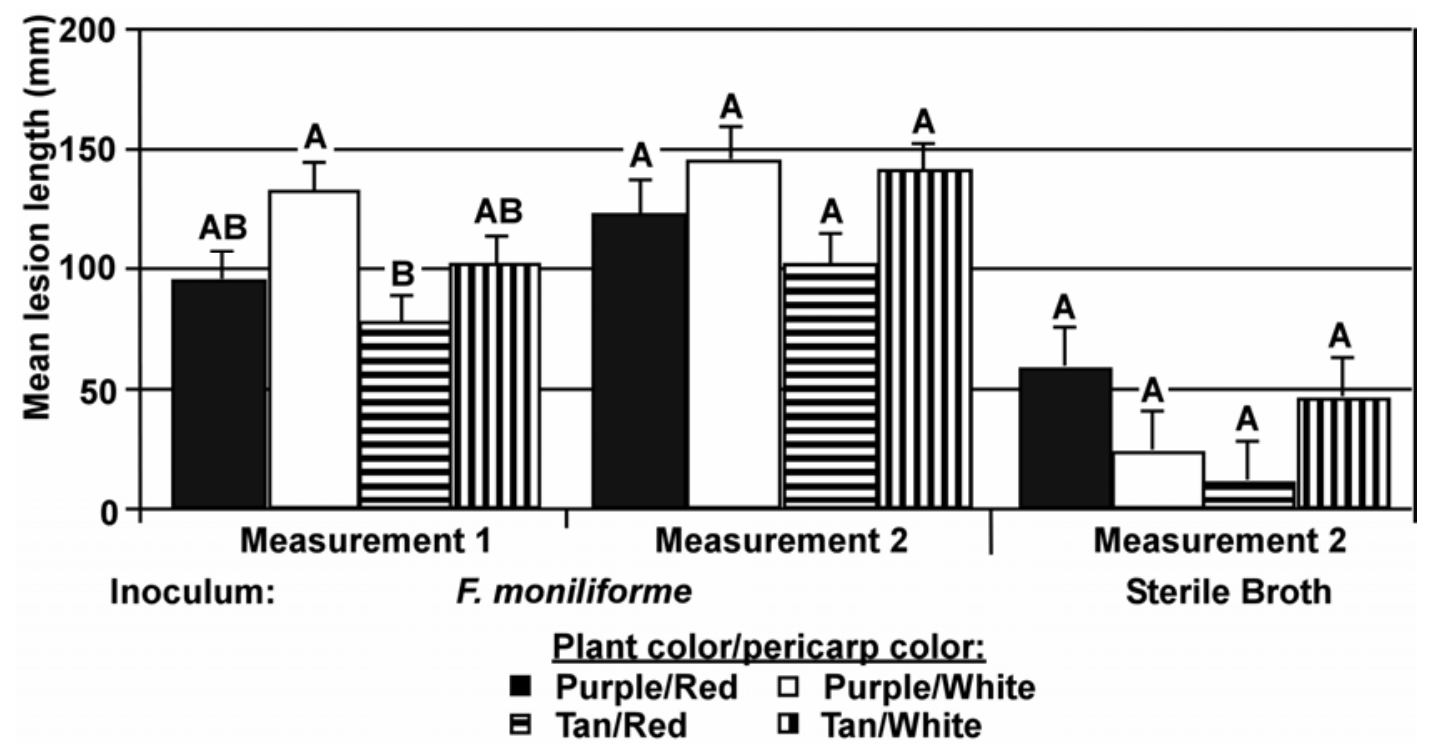

Fig. 3. Response of plant color/pericarp color lines to inoculation with a Fusarium moniliforme isolate pathogenic on sorghum and to inoculation with sterile broth: assay 2. Mean (LSM) lesion measurements $(\mathrm{mm}) 18$ days following inoculation of plant color/pericarp color lines with toothpicks incubated in broth with $F$. moniliforme or with toothpicks incubated in sterile broth by plant phenotype. Twenty-one purple/red plants, 15 purple/white plants, and 18 each of tan/red plants and tan/white plants were inoculated with $F$. moniliforme. Ten plants each of purple/red, purple/white, and tan/white phenotypes and 11 plants of the tan/red phenotype were inoculated with sterile broth. For inoculations with $F$. moniliforme, the first and second measurements are shown while the second measurement is shown for inoculations with sterile broth. Positive standard errors are shown. Bars marked with different letters are statistically significant at $P \leq 0.05$. 
tween the mean lesion lengths resulting from inoculation of purple plants or tan plants with $F$. moniliforme when considering the second measurement (Fig. 4). In assay 4 , significant differences between the mean lengths of the first measurement $(P=0.023)$, but not the second $(P=$ 0.1832 ), resulted following inoculation with $F$. moniliforme (Fig. 4B). Inoculation of each plant color/pericarp color phenotype with sterile broth resulted in mean measurements significantly less than those following inoculation with $F$. moniliforme
$(P<0.0001)$, but there were no interactions with plant phenotype. There were no significant differences indicated between tan and purple plants following mockinoculation with toothpicks incubated in sterile broth (Fig. 4).

In summary, a screen of plant color/ pericarp color near-isogenic lines for colonization or infection by Alternaria and Fusarium spp. provided evidence that white sorghum grain grown on tan plants may not have increased susceptibility to colonization by members of these genera

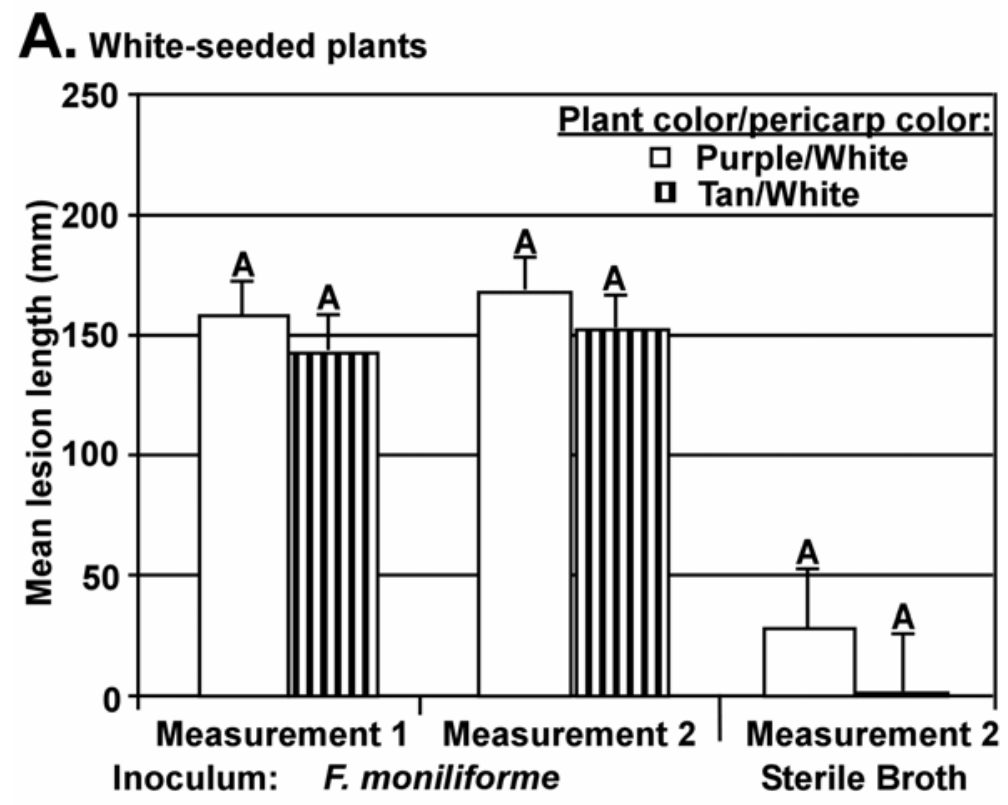

B. Red-seeded plants

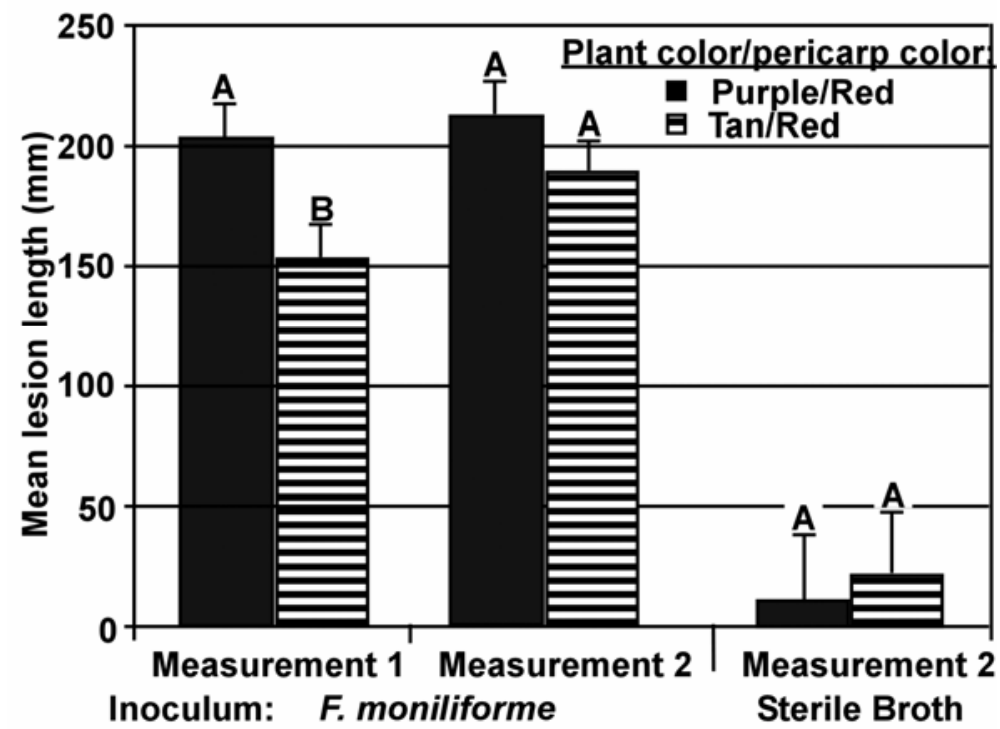

Fig. 4. Comparison of responses of purple plants with tan plants for plants with the same pericarp genotype to inoculation with Fusarium moniliforme or sterile broth. Measurements were made 22 days following inoculation. Measurements 1 and 2 following inoculation with F. moniliforme and measurement 2 following inoculation with sterile broth are shown. Mean (LSM) lesion measurements (mm) and positive standard errors are shown. Bars having different numbers within a measurement are statistically significant at $P \leq 0.05$. A, Plants with the white pericarp genotype. Twenty-seven plants of each phenotype, purple/white and tan/white, were inoculated with $F$. moniliforme, and 10 plants of each phenotype were inoculated with sterile broth. B, Plants with the red pericarp genotype. Twenty-three purple/red plants and 27 tan/red plants were inoculated with $F$. moniliforme, while 9 purple/red plants and $10 \tan /$ red plants were inoculated with sterile broth.

as compared to purple plants with red seed. In these controlled greenhouse assays, tan plants yielded lesions not significantly different from those produced on purple plants following inoculation with an Alternaria isolate and $F$. moniliforme, or significantly smaller lesions following inoculation with $F$. moniliforme. When screening seed from plants grown at Ithaca in 2002 and at Lincoln in 2003, there were no consistent results suggesting that white seed from tan plants was more susceptible to these fungal groups than red seed from purple plants. However, when seed from Lincoln, 2003, was selected on PCNB, significantly greater numbers of Fusarium isolations other than $F$. moniliforme were obtained from seed of tan plants when compared with seed from purple plants. This suggested that pigments involved in conferring the purple wound response may be involved in protecting these lines, and perhaps the developing grain, from colonization by Fusarium species.

\section{DISCUSSION}

Traits that previously have been associated with resistance to infection in sorghum grain by fungi are a pigmented wound response $(46,50)$ and grain with a pigmented pericarp $(10,48)$. However, sorghum desirable for livestock and for humans would lack these traits $(4,39)$. Concern had been raised that lines with white grain on tan plants may be more susceptible to grain mold fungi $(2,10,17,26,39)$. However, in this study, there was no evidence that tan sorghum plants that produce white seed were significantly and consistently more susceptible to members of the genera Alternaria and Fusarium, suggesting that at least some of these lines may be useful in the production of food-grade grain.

Plant color/pericarp color near-isogenic lines (39) were screened for response to colonization by fungi following wound inoculation of the peduncle with an Alternaria sp. isolate and an $F$. moniliforme isolate pathogenic on sorghum. In the first inoculation assay, plants having either the purple color or the trait for grain with red pericarp resulted in significantly greater mean lesion lengths than plants with the $\tan$ color phenotype or the trait for white seed when plant color/pericarp color lines were inoculated with an $F$. moniliforme isolate (Fig. 2). Pigments involved in producing the purple wound response $(30,31)$, which may include that involved in imparting red pericarp color (7), may have responded to the wound that initiated the inoculation (18). Therefore, in later assays, toothpicks incubated in sterile broth also were used to inoculate plants alongside those inoculated with $F$. moniliforme. Over four assays, there was no consistent indication that wounding alone accounted for the differences in mean lesion lengths between purple and tan plants in assay 1 (Figs. 2 to 
4). Additionally, wounding and infection of tan plants can result in a discernable response (Fig. 1A, B, and D). It is possible that wounding with sterile broth could have resulted in infections with other microorganisms (25). Therefore, this control also can assist in accounting for incidental infections that may affect lesion size following inoculation with a pathogen of interest. In assay 3, secondary infections by what appeared to be bacteria at the point of inoculation were noted in three $F$. moniliforme-inoculated plants (one purple/white plant and two tan/white plants), but no such infections were visually apparent in plants wound-inoculated with sterile broth in assay 3 or in plants inoculated by fungi or wound-inoculated with sterile broth during other assays (data not shown).

The role that pigments in nonreproductive parts of plants could play in development of grain mold is indirect. It has been shown that some pigments produced in response to pathogen invasion of leaves and other plant parts $(31,47)$ are inhibitory to fungi $(46,47)$ and are associated with resistance to grain mold fungi $(17,26)$. It has been well-documented that $F$. moniliforme infection of maize plants can result in colonization of grain $(27,35)$. Therefore, pigments in plant parts other than in the developing seed could conceivably prevent infection of grain. When seed collected from randomly chosen plots grown at Lincoln in 2003 was plated onto two different media, DCPA and PCNB $(1,28)$, seed grown on purple plants appeared to have increased numbers of Alternaria species and a decreased number of $F$. moniliforme isolations (Tables 3 and 4). An inverse relationship between colonization of wheat grain by Fusarium graminearum Schwabe and Alternaria alternata (Fr.) Keissl. (14) and of wheat, barley, and oats by Alternaria species and Fusarium species (21) have been previously reported. The present work provides evidence that pigments in nonreproductive plant parts may protect sorghum grain from colonization or infection by Fusarium spp.

Pericarp color may more directly affect fungal colonization $(10,48)$. When seeds collected from plant color/pericarp color plants grown at Ithaca in 2002 were plated onto DCPA, white grain had significantly less total fungal isolations per seed and significantly less Alternaria isolations per seed (Table 2). In all other measurements on either media, there were no significant differences when comparing red grain with white grain grown at both locations, in both years (Tables 2 to 4 ). This suggests that the red pericarp trait does not provide increased protection against colonization by Alternaria and Fusarium in these nearisogenic lines. A possible explanation may be that another quality, such as grain hardness, is involved in resistance to these fungi in white grain. The fact that grain hardness can contribute to resistance to grain mold fungi is well-established $(19,48)$. However, for the lines tested in the present study, the small differences in grain hardness were unlikely to contribute to or detract from response to infection in any given phenotype.

A difference in response of the same lines in two environments was noted. Environmental effects on grain mold incidence in sorghum have been previously reported $(19,41)$. The conditions at Ithaca in 2002 appeared to allow for distinction of lines having different plant colors and pericarp colors (Table 2; 41). This may in part be due to increased moisture (irrigation and greater rainfall totals; Table 1) or pathogen spread (37) at Ithaca in 2002, a factor reported to affect incidence of colonization of grain by fungi (43). Differences in rainfall and irrigation may result in microclimates within the canopy that are conducive to infection by fungi $(9,13)$. Another possible difference between the two locations and years is that the grain grown at Ithaca in 2002 was left on plants for up to 6 weeks following the earliest maturity date, while the grain grown at Lincoln in 2003 was harvested at maturity (Table 1). A delayed harvest could have subjected the grain to weathering, and consequently, caused it to be more vulnerable to bird damage, insects, and pathogens $(43,49)$. Visual observation of seed from both locations and years did not reveal significant weathering or other obvious damage to seed that would account for the observed results between the two plantings. It also was noted that fungi isolated from seed grown at the two locations in different years were not identical. There were greater numbers of different Fusarium spp. isolated from Ithaca in 2002 than from seed grown in Lincoln in 2003. On the other hand, two species ( $F$. acuminatum and $F$. equiseti) were isolated from seed grown at Lincoln in 2003, but were not detected in seed grown at Ithaca in 2002.

\section{ACKNOWLEDGMENTS}

We thank J. Toy for conducting field plantings and B. Tlamka for conducting greenhouse assays. We also thank J. Soper and A. Wagner for technical assistance. We thank D. C. Stenger for providing helpful editorial suggestions and for assistance in figure preparation.

\section{LITERATURE CITED}

1. Andrews, S., and Pitt, J. I. 1986. Selective medium for isolation of Fusarium species and Dematiaceous Hyphomycetes from cereals. Appl. Environ. Microbiol. 51:1235-1238.

2. Audilakshmi, S., Stenhouse, J. W., Reddy, T. P., and Prasad, M. V. R. 1999. Grain mould resistance and associated characters of sorghum genotypes. Euphytica 107:91-103.

3. Awika, J. M., Rooney, L. W., and Waniska, R. D. 2004. Properties of 3-deoxyanthoxyanins from sorghum. J. Agric. Food Chem. 52:43884394.

4. Awika, J. M., Suhendro, E. L., and Rooney, L. W. 2002. Milling values of sorghums compared by adjusting yields to a constant product color. Cereal Chem. 79:249-251.

5. Bandyopadhyay, R., Mughogho, L. K., and
Prasada Rao, K. E. 1988. Sources of resistance to sorghum grain molds. Plant Dis. 72:504508.

6. Castor, L. L., and Frederiksen, R. A. 1981. Grain deterioration in sorghum. Pages 163-169 in: Proceedings of the International Symposium on Sorghum Grain Quality. ICRISAT, Patencheru, India.

7. Chopra, S., Gevens, A., Svabek, C., Wood, K V., Peterson, T., and Nicholson, R. L. 2002. Excision of the Candystripe1 transposon from a hypermutable $Y 1$-cs allele shows that the sorghum $Y 1$ gene controls the biosynthesis of both 3-deoxyanthocyanidin phytoalexins and phlobaphene pigments. Physiol. Mol. Plant Pathol. 60:321-330.

8. Dreyer, D. L., Reese, J. S., and Jones, K. C. 1981. Aphid feeding deterrents in sorghum: Bioassay, isolation and characterization. J. Chem. Ecol. 7:273-284.

9. Emery, K. M., and English, J. T. 1994. Development of foliar diseases of alfalfa in relation to microclimate, host growth, and fertility. Phytopathology 84:1263-1269.

10. Esele, J. P., Frederiksen, R. A., and Miller, F. R. 1993. The association of genes controlling caryopsis traits with grain mold resistance in sorghum. Phytopathology 83:490-495.

11. Etzel, R. A. 2005. Mycotoxins and human disease. Pages 449-275 in: Microbial Toxins: Molecular and Cellular Biology. Horizon Bioscience, Norwich, UK.

12. Freeman, J. E., and Watson, S. A. 1971. Influence of sorghum endosperm pigments on starch quality. Cereal Sci. Today 16:378-381.

13. Giesler, L. J., Yuen, G. Y., and Horst, G. L. 1996. The microclimate in tall fescue turf as affected by canopy density and its influence on brown patch disease. Plant Dis. 80:389-394.

14. González, H. H. L., Martínez, E. J., Pacin, A. and Resnik, S. L. 1999. Relationship between Fusarium graminearum and Alternaria alternata contamination and deoxynivalenol occurrence on Argentinian durum wheat. Mycopathologia 144:97-102.

15. Gordon, W. L. 1952. The occurrence of Fusarium species in Canada. II. Prevalence and taxonomy of Fusarium species in cereal seed. Can. J. Bot. 30:209-251.

16. Hsu, T. S. 1936. Resistance of sorghum to stem borers. J. Am. Soc. Agron. 28:271-278.

17. Jambunathan, R., Butler, L. G., Bandyopadhyay, R., and Mughogho, L. K. 1986. Polyphenol concentrations in grain, leaf, and callus tissues of mold-susceptible and mold-resistant sorghum cultivars. J. Agric. Food Chem. 34:425-429.

18. Jardine, D. J., and Leslie, J. F. 1992. Aggressiveness of Gibberella fujikuroi (Fusarium moniliforme) isolates to grain sorghum under greenhouse conditions. Plant Dis. 76:897-900.

19. Klein, R. R., Rodriquez-Herrera, R., Schlueter, J. A., Klein, P. E., Yu, Z. H., and Rooney, W. L. 2001. Identification of genomic regions that affect grain-mould incidence and other traits of agronomic importance in sorghum. Theor. Appl. Genet. 102:307-319.

20. Klittich, C. J. R., Leslie, J. F., Nelson, P. E., and Marasas, W. F. O. 1997. Fusarium thapsinum (Gibberella thapsina): A new species in section Liseola from sorghum. Mycologia 89:643-652.

21. Kosiak, B., Torp, M., Skjere, E., and Andersen, B. 2004. Alternaria and Fusarium in Norwegian grains of reduced quality-A matched pair sample study. Int. J. Food Microbiol. 93:51-62.

22. LeBeau, F. J., and Coleman, O. H. 1950. The inheritance of resistance in sorghum to leaf anthracnose. Agron. J. 42:33-34.

23. Leslie, J. F. 1995. Gibberella fujikuroi: Available populations and variable traits. Can. J. Bot. 73(Suppl. 1):S282-S291

24. Leslie, J. F., Plattner, R. D., Desjardins, A. E., and Klittich, C. J. R. 1992. Fumonisin B 1 pro- 
duction by strains from different mating populations of Gibberella fujikuroi (Fusarium section Liseola). Phytopathology 82:341-345.

25. Leslie, J. F., Zeller, K. A., Lamprecht, S. C., Rheeder, J. P., and Marasas, W. F. O. 2005. Toxicity, pathogenicity, and genetic differentiation of five species of Fusarium from sorghum and millet. Phytopathology 95:275283.

26. Melake-Berhan, A., Butler, L. G., Ejeta, G., and Menkir, A. 1996. Grain mold resistance and polyphenol accumulation in sorghum. $\mathrm{J}$. Agric. Food Chem. 44:2428-2434.

27. Munkvold, G. P., McGee, D. C., and Carlton, W. M. 1997. Importance of different pathways for maize kernel infection by Fusarium moniliforme. Phytopathology 87:209-217.

28. Nash, S. M., and Snyder, W. C. 1962. Quantitative estimates by plate counts of propagules of the bean root rot Fusarium in field soils. Phytopathology 52:567-572.

29. Nelson, P. E., Tousson, T. A., and Marasas, W. F. O. 1983. Fusarium Species: An Illustrated Manual for Identification. Pennsylvania State University Press, University Park.

30. Nicholson, R. L., Jamil, F. F., Snyder, B. A., Lue, W. L., and Hipskind, J. 1988. Phytoalexin synthesis in the juvenile sorghum leaf. Physiol. Mol. Plant Pathol. 33:271-278.

31. Nicholson, R. L., Kollipara, S. S., Vincent, J. R., Lyons, P. C., and Cadena-Gomez, G. 1987. Phytoalexin synthesis by the sorghum mesocotyl in response to infection by pathogenic and non pathogenic fungi. Proc. Natl. Acad. Sci. USA 84:5520-5534.

32. Nip, W. K., and Burns, E. E. 1969. Pigment characterization in grain sorghum. Cereal Chem. 46:490-495.

33. Nirenberg, H. 1976. Untersuchungen über die morphologische und biologishe Differenzierung in der Fusarium-Sektion Liseola. Mitt. Biol. Bundesanst. Lan Forstwirtsch.
Berlin Dahlem. 169:1-117.

34. Nirenberg, H. I., and O'Donnell, K. 1998. New Fusarium species and combination within the Gibberella fujikoroi species complex. Mycologia 90:434-458.

35. Oren, L., Ezrati, S., Cohen, D., and Sharon, A. 2003. Early events in the Fusarium verticillioides-maize interaction characterized by using a green fluorescent protein-expressing transgenic isolate. Appl. Environ. Microbiol. 69:1695-1701.

36. Padule, D. N., and Salunkhe, D. K. 1984. Effects of diseases on yield and quality of grain sorghum. Pages 231-254 in: Nutritional and Processing Quality of Sorghum. Oxford and IBH Publishing, Co., New Delhi.

37. Paul, P. A., El-Allaf, S. M., Lipps, P. E., and Madden, L. V. 2004. Rain splash dispersal of Gibberella zeae within wheat canopies in Ohio. Phytopathology 94:1342-1349.

38. Pedersen, J. F., Martin, C. R., Felker, F. C., and Steele, J. L. 1996. Application of the single kernel wheat characterization technology to sorghum grain. Cereal Chem. 73:421-423.

39. Pedersen, J. F., and Toy, J. J. 2001. Germination, emergence, and yield of 20 plant-color, seed-color near-isogenic lines of grain sorghum. Crop Sci. 41:107-110.

40. Puhalla, J. E. 1981. Genetic considerations of the genus Fusarium. Pages 291-305 in: Fusarium: Diseases, Biology and Taxonomy. Pennsylvania State University Press, University Park.

41. Rodriguez-Herrera, R., Rooney, W. L., Rosenow, D. T., and Frederiksen, R. A. 2000. Inheritance of grain mold resistance in grain sorghum without a pigmented testa. Crop Sci. 40:1573-1578

42. Scudamore, K. A., and Livesey, C. T. 1998. Occurrence and significance of mycotoxins in forage crops and silage: A review. J. Sci. Food Agric. 77:1-17
43. Seitz, L. M., Mohr, H. E., Burroughs, R., and Glueck, J. A. 1983. Preharvest fungal invasion of sorghum grain. Cereal Chem. 60:127-130.

44. Siame, B. A., Ejeta, G., and Butler, L. G. 1994 Role of pigments and tannins in the reaction of tan and red near-isogenic sorghum lines to leaf diseases. Acta Hortic. 381:675-678.

45. Singh, B. U., Padmaja, P. G., and Seetharama, N. 2004. Biology and management of the sugarcane aphid, Melanaphis sacchari (Zehntner) (Homoptera: Aphididae), in sorghum: A review. Crop Prot. 23:739-755.

46. Snyder, B. A., Leite, B., Hipskind, J., Butler, L. G., and Nicholson, R. L. 1991. Accumulation of sorghum phytoalexins induced by $\mathrm{Col}$ letotrichum graminicola at the infection site. Physiol. Mol. Plant Pathol. 39:463-470.

47. Snyder, B. A., and Nicholson, R. L. 1990. Synthesis of phytoalexins in sorghum as a sitespecific response to fungal ingress. Science 248:1637-1639.

48. Waniska, R. D., Venkatesha, R. T., Chandrashekar, A., Krishnaveni, S., Bejosano, F. P., Jeoung, J., Jayaraj, J., Muthukrishnan, S., and Liang, G. H. 2001. Antifungal proteins and other mechanisms in the control of sorghum stalk rot and grain mold. J. Agric. Food Chem. 49:4732-4742.

49. Webley, D. J., Jackson, K. L., Mullins, J. D. Hocking, A. D., and Pitt, J. I. 1997. Alternaria toxins in weather-damaged wheat and sorghum in the 1995-1996 Australian harvest. Aust. J. Agric. Res. 48:1249-1255

50. Wharton, P. S , and Julian, A. M. 1996 . A cytological study of compatible and incompatible interactions between Sorghum bicolor and Colletotrichum sublineolum. New. Phytol. 134:25-34.

51. Wozniak, C. A., and Partridge, J. E. 1988 Analysis of growth in sorghum callus cultures and association with a $27 \mathrm{kD}$ peptide. Plant Sci. 57:235-246. 